\title{
Rancang Bangun Pengereman Motor Direct Current Pada Mobil Listrik
}

\author{
Muhammad Ali Faisal Fadhilah', Cornelius Sarri ${ }^{2}$, Masing $^{3}$ dan Prihadi Murdiyat ${ }^{4 *}$ \\ 1,2,3,4 Jurusan Teknik Elektro, Politeknik Negeri Samarinda, Indonesia \\ *pmurdiyat@polnes.ac.id
}

\begin{abstract}
This article presents the research outcome of design, implementation, and testing of dynamic braking applied on the electric car prototype developed in Electrical Department, Politeknik Negeri Samarinda. The purpose of the research is to evaluate the performance of dynamic braking in stopping the car. The dynamic braking is provided by setting up a variable resistor that both terminals are parallel connected to the DC motor to provide a close loop circuit. The testing is undertaken in three stages. At the first and second stage, the car is tested stationery in the Electrical Department Laboratory. In the first stage, the DC motor is evaluated without any load, while at the second stage, the DC motor is connected to the rear wheel through gears and chain. The bottom of the car is wedged to enable the wheel to rotate. In the third stage, the load is the car itself and a driver. The observation is undertaken by measuring the stopping distance after the car is braked at the speed of $9 \mathrm{~m} / \mathrm{s}$, where three resistor values of the dynamic brake are applied. For the first stage, the results show that at the constant rotation speed of 3000 rpm and the highest resistance (365 $\Omega$ ) the motor shaft will stop at 3.13 seconds. Meanwhile, for the resistance of $60 \Omega$, the shaft will stop at 1.61 second. For the second stage, where the rotation speed is converted into linier speed, it is found that with the speed of $9 \mathrm{~m} / \mathrm{s}$ and the resistance of $365 \Omega$, the braking time reaches 5.54 second. Furthermore, with the resitance of $60 \Omega$ the braking time is 3.336 seconds. For the third stage the observation was undertaken on the campus flat road, With the resistance of $90 \Omega, 70 \Omega$, and 50 $\Omega$, the braking distance is $38.3 \mathrm{~m}, 32.3 \mathrm{~m}, 18.2 \mathrm{~m}$ respectively.
\end{abstract}

Keywords: Electric car; Brushed DC motor; Dynamic braking; Resistor

\begin{abstract}
Abstrak: Artikel ini mempresentasikan hasil penelitian berupa rancang bangun pengereman dinamik dan pengujiannya pada prototipe mobil listrik yang dikembangkan di Jurusan Teknik Elektro Politeknik Negeri Samarinda. Tujuan penelitian ini adalah untuk menguji kemampuan pengereman dinamik dalam menghentikan laju mobil listrik. Pengereman dinamik dilakukan dengan mengatur nilai tahanan variable yang kedua ujungnya dihubungkan dengan motor untuk mendapatkan rangkaian lup tertutup. Pengujian dilakukan dengan tiga cara. Pada cara pertama dan kedua, mobil diuji secara stasioner di Laboratorium Jurusan Teknik Elektro. Pengujian pertama dilakukan ketika motor DC penggerak mobil tidak dibebani. Pada cara kedua, motor DC dihubungkan dengan roda bagian belakang dengan menggunakan rantai dan gir. Agar roda bergerak dengan bebas, bagian bawah mobil diganjal. Pada pengujian ketiga, beban adalah badan mobil secara keseluruhan dan seorang supir. Pengujian dilakukan untuk mengukur jarak yang ditempuh ketika rem dengan tiga resistansi berbeda diaktifkan pada kecepatan $9 \mathrm{~m} /$ detik. Pada pengujian pertama, dengan putaran konstan sebesar $3000 \mathrm{rpm}$ dan nilai tahanan tertinggi sebesar $365 \Omega$ didapat waktu pengereman hingga poros motor berhenti selama 3.13 detik. Untuk nilai tahanan $60 \Omega$ diperoleh waktu pengereman 1.61 detik. Pada pengujian kedua, di mana kecepatan putar dikonversi menjadi kecepatan, diperoleh bahwa dengan kecepatan $9 \mathrm{~m} / \mathrm{s}$ dan tahanan tertinggi sebesar $365 \Omega$, waktu pengeremannya mencapai 5.54 detik. Untuk nilai tahanan $60 \Omega$ diperoleh waktu pengereman 3.336 detik. Untuk pengujian ketiga, mobil diuji saat dijalankan di area datar di kampus Politeknik. Dengan menggunakan tiga jenis nilai tahanan yaitu: $90 \Omega, 70 \Omega$, dan $50 \Omega$, jarak mobil dari saat pertama pengereman hingga berhenti berturut-turut adalah: $38.3 \mathrm{~m}$, $32.3 \mathrm{~m}, 18.2 \mathrm{~m}$.
\end{abstract}

Kata kunci : Mobil listrik; Motor brushed DC; Pengereman dinamik; Tahanan

\section{PENDAHULUAN}

Motor adalah mesin yang dapat mengubah energy listrik menjadi energi mekanis. Pada motor DC (Direct Current) sumber tegangan listrik arus searah dihubungkan pada rangkaian medan dan 
rangkaian jangkar agar motor berputar. Motor arus searah dapat dijumpai pada alat pengangkut pertambangan, sarana transportasi kereta api listrik, dan mobil listrik.

Dalam menggunakan motor DC untuk keperluan-keperluan tersebut di atas, pengereman merupakan salah satu masalah yang sangat penting karena motor yang sedang berputar tidak dapat berhenti begitu saja walaupun suplai tegangan telah diputuskan. Sehingga untuk memperlambat atau menghentikn putaran motor diperlukan sistem pengereman. Pengereman mekanis biasa tidak bisa menghentikan motor DC, karena ketika direm secara mekanis arus yang sangat besar akan mengalir pada kumparan jangkar motor. Arus ini dapat menimbulkan panas dan kerusakan pada motor. Oleh sebab itu, pengereman secara elektrik sangat diperlukan.

Mobil listrik saat ini sudah diproduksi masal. Pengembangannya juga mulai dilakukan oleh banyak pihak, termasuk mahasiswa Jurusan Teknik Elektro di beberapa perguruan tinggi [1]. Mobil listrik didesain untuk menggunakan teknologi mesin dengan penggerak energi listrik, sehingga diharapkan mampu menekan tingkat polusi udara, dan menjadi mobil yang ramah lingkungan [2].

Sama halnya dengan mobil berbahan bakar minyak, mobil listrik juga mampu melaju dengan kecepatan tinggi, sehingga juga mempunyai resiko mengalami kecelakaan. Untuk meningkatkan keselamatan pengguna mobil listrik, diperlukan sistem kendali rem yang baik [3].

Penelitian ini membahas tentang rancang bangun sistem pengereman listrik jenis dinamik untuk diuji pada protipe mobil listrik yang telah dibuat untuk melengkapi penelitian ini.

\section{METODE PENELITIAN}

Sebelum melakukan rancang bangun yang perlu dilakukan adalah memahami jenis motor penggerak yang digunakan oleh mobil listrik. Jenis motor yang digunakan adalah motor brushed DC. Sesuai namanya, motor DC memerlukan tegangan arus searah atau DC untuk dapat menggerakannya. Motor listrik DC ini biasanya digunakan pada perangkat-perangkat elektronik dan listrik yang menggunakan sumber listrik DC [4].

Motor brushed DC menggunakan sistem mekanis commutated dengan sumber arus searah (DC). Komponen utama motor brushed DC adalah stator, rotor dan sistem komutasi mekanis. Konstruksi motor brushed DC ditunjukan dalam Gambar 1.

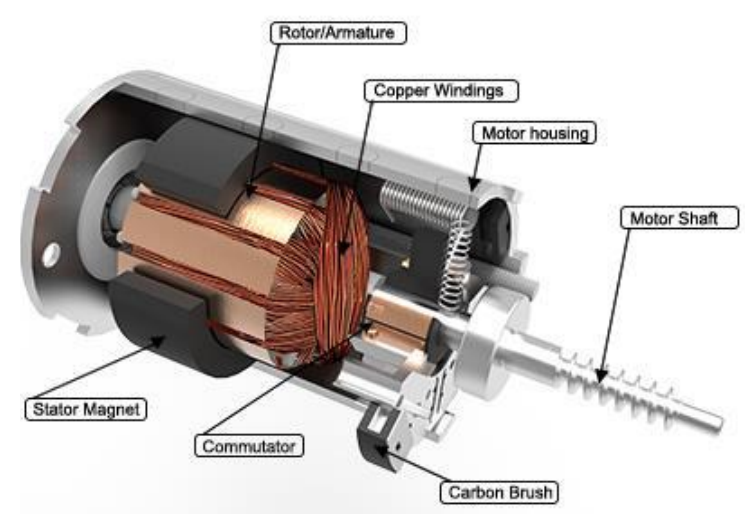

Gambar 1. Kontruksi Motor Brushed DC [5]

Stator dalam motor brushed DC ini kebanyakan berupa magnet permanen. Namun terkadang juga ada yang berupa dalam bentuk kumparan yang berada pada inti besi. Rotor pada motor jenis ini biasanya berupa kumparan yang digulung dalam suatu inti besi. Agar kumparan pada rotor dapat dihubungkan dengan sumbe rlistrik, maka digunakan komutator. Motor brushed DC menggunakan sistem mechanical commutated di mana sepasang brushed yang terbuat dari karbon akan bersentuhan dengan komutator. 
Motor brushed DC memiliki konstruksi yang tidak begitu rumit. Dari desain konstruksinya, motor brushed mempunyai kelebihan dan kekurangan sebagai berikut [6]:

Kelebihannya:

1. Lebih ringan karena dua magnet saja sudah cukup untuk dapat berputar sehingga gaya inersia relatif rendah.

2. Tidak memerlukan control drive untuk dapat menggerakkannya.

3. Lebih mudah dalam pengaturan kecepatannya.

4. Harga dari motor ini relatif murah

Sedangkan kekurangan dari motor ini yaitu:

1. Mengeluarkan suara berisik karena gesekan antara brush dan komutator

2. Banyak kerugian gesekan

3. Karena jumlah magnet tidak terlalu banyak motor ini cenderung memiliki daya output yang kecil.

4. Usia motor tidak terlalu panjang.

Pada penelitian ini dipilih jenis pengereman dinamik karena merupakan metode pengereman motor listrik yang praktis dan memberikan gaya pengereman yang baik. Jenis pengereman ini sangat efisien untuk waktu yang sangat singkat karena motor dapat berhenti dengan cepat.

Pengereman dinamik dilakukan dengan memasang beban RL pada terminal setelah tegangan sumber diputuskan. Karena motor arus searah tidak dapat berhenti secara mendadak, maka setelah tegangan sumber dimatikan kecepatan putaran motor masih relatif tinggi. Pada saat demikian motor berubah fungsi menjadi generator. Untuk menghentikan putaran motor setelah tegangan sumber dimatikan terminal motor dihubungkan dengan beban RL. Beban tersebut menyebabkan putaran jangkar turun dengan cepat. Hal yang perlu diperhatikan adalah bahwa harga RL perlu dipilih sedemikian rupa sehingga arus IL tidak terlalu besar (biasanya dua kali arus jangkar beban penuh) [7]. Rangkaian pengereman dinamik dapat dilihat pada Gambar 2.

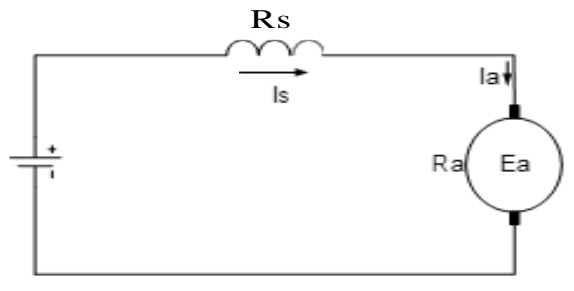

a. Sebelum pengereman

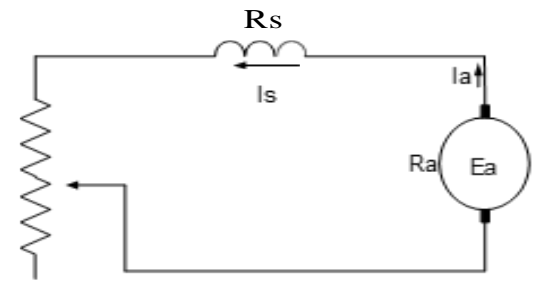

b. Saat Pengereman

Gambar 2 Rangkaian Pengereman Dinamik Motor DC [8]

Rangkaian jenis pengereman dinamik motor arus searah ini dapat dikendalikan dengan menggunakan kontaktor magnetik. Dengan cara meng-energize sebuah coil pada sebuah rangkaian control yang mengendalikan semua kontaktor magnetic pada rangkaian jenis pengereman dinamik motor $D C$, maka motor tersebut akan secara otomatis melakukan pengereman tanpa harus melakukan penekanan saklar secara manual.

Kontaktor magnetic yang digunakan berupa relay, yaitu saklar (switch) yang dioperasikan secara listrik dan merupakan komponen electromechanical (elektromekanikal) yang terdiri dari 2 bagian utama yakni bagian elektromagnet (coil) dan mekanikal (seperangkat kontak saklar/switch). Relay menggunakan prinsip elektromagnetik untuk menggerakkan kontak saklar sehingga dengan arus listrik yang kecil (low power) dapat menghantarkan listrik yang bertegangan lebih tinggi. Bentuk relay 
ditunjukkan dalam Gambar 3. Pada pengereman dinamik dalam penelitian ini relay digunakan untuk memutus atau menghubungkan sumber listrik ke motor.

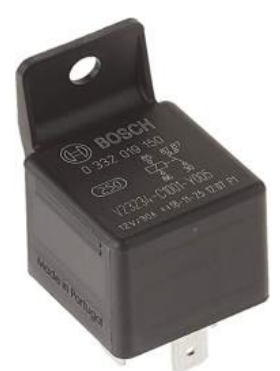

Gambar 3. Relay [8]

Prototipe mobil yang digunakan pada penelitian ini menggunakan kerangka yang terbuat dari material besi hollow dengan ukuran $3 \mathrm{~cm}$ x $3 \mathrm{~cm}$ dengan ketebalan $2 \mathrm{~mm}$. Kerangka harus mempunyai konstruksi yang kuat untuk menahan beban komponen dan penumpang. Dengan menggunakan perangkat lunak Autodesk desain bentuk kerangka, beserta ukuran dimensinya ditunjukkan dalam Gambar 4.
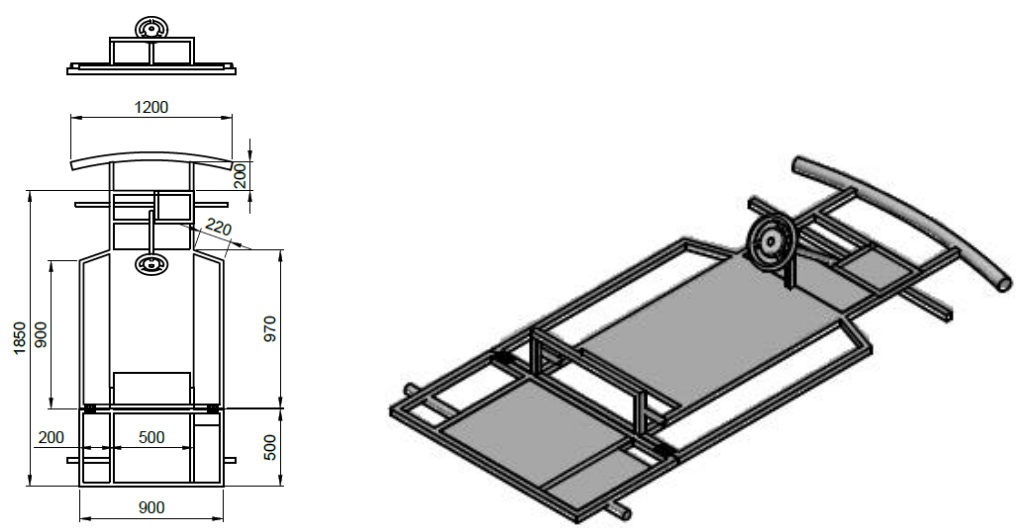

Gambar 4. Dimensi dan Bentuk Kerangka Mobil Dalam Bentuk 3D.

Sedangkan rangkaian sistem pengereman dinamiknya ditunjukkan dalam Gambar 5. Aktif tidaknya relay diatur oleh program dalam board Arduino. Ketika relay memutuskan motor dari suplainya, pengereman dilakukan dengan mengatur nilai resistor variabel. Pengaturan resistor variable / potensiometer dilakukan dengan menekan pedal rem yang terhubung secara mekanis dengannya.

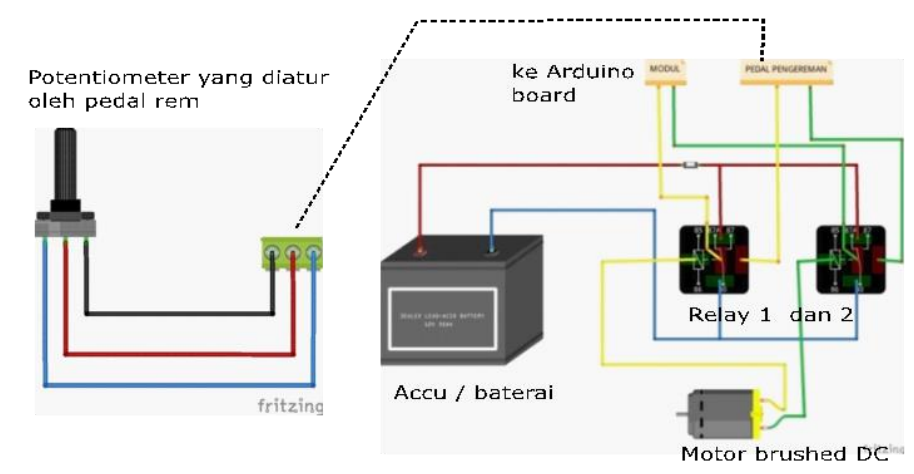

Gambar 5. Rancangan Sistem Pengereman 
116 Muhammad Ali Faisal Fadhilah, Cornelius Sarri, Masing, Prihadi Murdiyat. Rancang Bangun Pengereman Motor Direct Current Pada Mobil Listrik

\section{HASIL DAN PEMBAHASAN}

\section{A. Metode Pengujian Pengujian}

Pengujian dilakukan dalam tiga tahap. Pada tahap pertama dan kedua, mobil diuji secara stasioner di Laboratorium Jurusan Teknik Elektro. Pengujian pertama dilakukan ketika motor DC penggerak mobil tidak dibebani. Pada tahap kedua, motor DC dihubungkan dengan roda bagian belakang dengan menggunakan rantai dan gir, yang sekaligus menjadi bebannya. Agar roda bergerak dengan bebas, bagian bawah mobil diganjal. Pada pengujian ketiga, dilakukan pengujian di salah satu lokasi jalan yang datar di dalam Kampus Politeknik. Beban adalah badan mobil secara keseluruhan dan seorang supir. Pengujian dilakukan untuk mengukur jarak yang ditempuh ketika rem dengan tiga resistansi berbeda diaktifkan pada kecepatan $9 \mathrm{~m} /$ detik.

\section{B. Data Hasil Pengujian Tidak Berbeban}

Untuk pengujian tanpa beban, situasinya ditunjukan pada Gambar 6. Gir yang terhubung pada as motor diberi beri stiker hitam dan putih agar perbedaan warnanya dapat dikenali oleh tachometer.

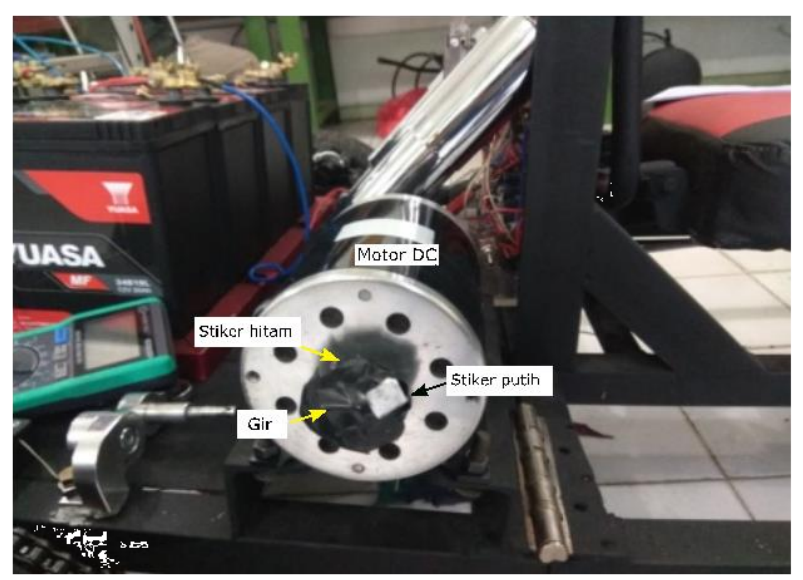

Gambar 6. Pengujian Motor Tidak Berbeban

Sebelum dilakukan pengujian pengereman, tegangan motor adalah $43 \mathrm{~V}$, arus motor $1.7 \mathrm{~A}$, dan kecepatan putar motor adalah $3000 \mathrm{rpm}$. Setelah dilakukan pengujian pengereman tanpa beban, diperoleh data pada Tabel 1.

Tabel 1 Data Pengereman Tidak Berbeban.

\begin{tabular}{|c|c|c|}
\hline Tahanan $(\Omega)$ & I rem (ampere) & Time (sec) \\
\hline 365 & 0.95 & 3.13 \\
\hline 300 & 0.99 & 2.95 \\
\hline 250 & 1.05 & 2.49 \\
\hline 200 & 1.43 & 2.44 \\
\hline 100 & 1.55 & 2.23 \\
\hline 60 & 1.67 & 1.61 \\
\hline
\end{tabular}

Dari data pada Tabel 1 dan data sebelum pengereman, dapat dihitung kecepatan pengereman dengan menggunakan persamaan (1) hingga (3), yang memberikan hasil seperti pada Tabel 2. 
Tabel 2. Data Pengereman Dinamik Tidak Berbeban Pada Tegangan 43 V.

\begin{tabular}{|c|c|c|c|}
\hline $\begin{array}{c}\text { Tahanan } \\
(\mathbf{\Omega})\end{array}$ & I rem (ampere) & Time (sec) & Kecepatan $(\mathbf{m} / \mathbf{s})$ \\
\hline 365 & 0.95 & 3.13 & 1.68 \\
\hline 300 & 0.99 & 2.95 & 1.75 \\
\hline 250 & 1.05 & 2.49 & 1.85 \\
\hline 200 & 1.43 & 2.44 & 2.52 \\
\hline 100 & 1.55 & 2.23 & 2.74 \\
\hline 60 & 1.67 & 1.61 & 2.95 \\
\hline
\end{tabular}

Dari Tabel 2, dapat dibuat grafik waktu pengereman dan arus pengereman fungsi nilai tahanan pengereman seperti pada Gambar 7.
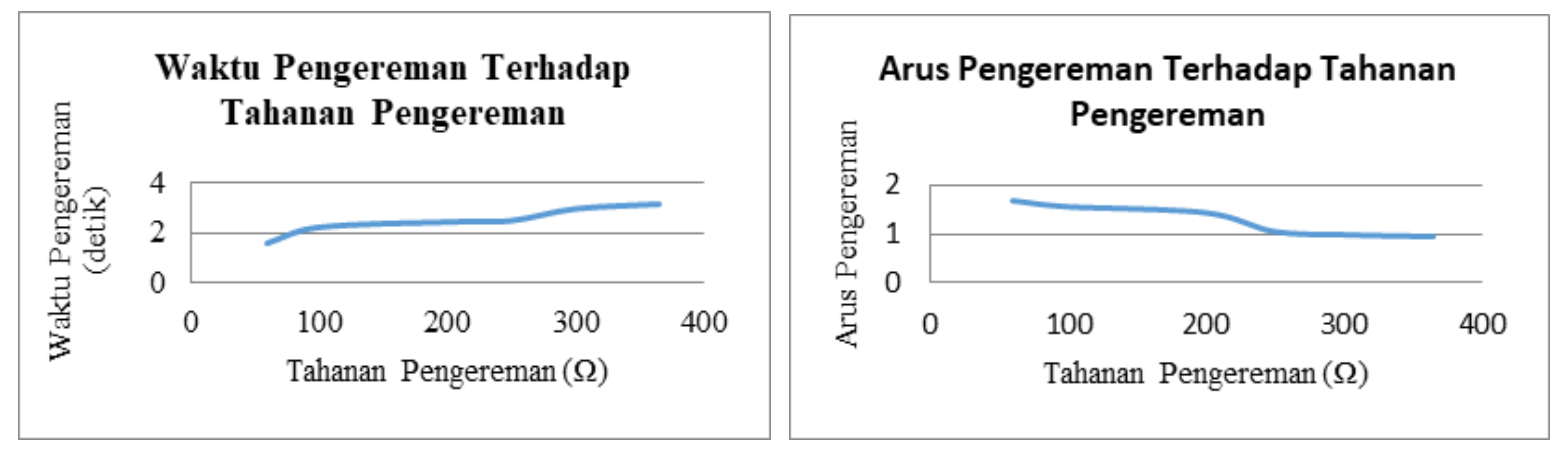

Gambar 7. Grafik Waktu dan Arus Pengereman Fungsi Nilai Tahanan Pengereman Pada Pengujian Tak Berbeban

Dari Gambar 7 tampak bahwa waktu pengereman akan semakin cepat jika nilai tahanannya semakin kecil. Dengan nilai tahanan pengereman yang paling kecil itu, arus pengereman yang dihasilkan akan paling besar.

\section{Data Hasil Pengujian Berbeban}

Pengujian berbeban dilakukan dengan memasang rantai pada gir motor dan gir roda seperti ditunjukan pada Gambar 8. Agar roda dapat berputar bebas, bagian bawah motor diganjal.

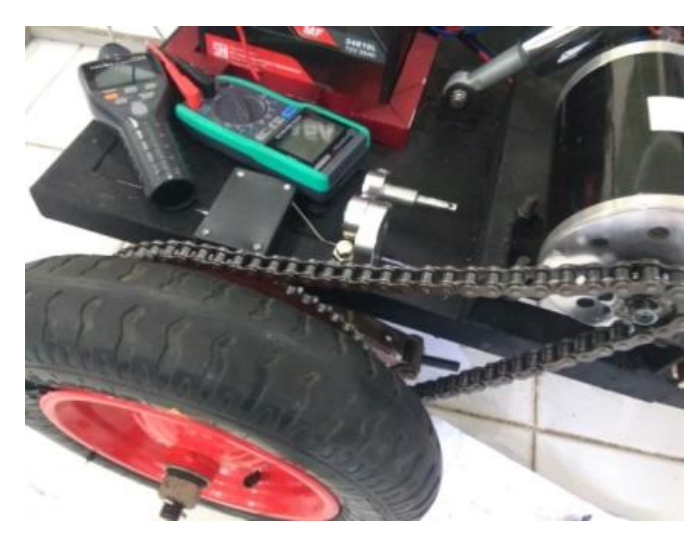

Gambar 8. Pengujian Motor Berbeban 
Sebelum dilakukan pengereman, motor diatur agar berputar pada kecepatan 9 meter/detik. Nilai ini diperoleh dari speedometer yang yang rangkain sensornya dipasang dekat gir roda belakang. Pada saat itu hasil pengukuran menunjukkan tegangan motor adalah sebesar $43 \mathrm{~V}$ dan arus motor adalah sebesar 1.7 A. Ketika dilakukan pengereman dengan beberapa nilai resistor, diukur arus pengereman dan waktu yang diperlukan agar roda benar-benar berhenti. Serupa dengan pengujian pertama, dari kedua parameter tersebut dapat diperoleh kecepatan pengereman dengan menggunakan persamaan (1) hingga (3). Hasil pengukuran dan perhitungan dari proses tersebut ditunjukkan pada Tabel 3.

Tabel 3. Data Pengereman Dinamik Berbeban Pada Tegangan 43 V

\begin{tabular}{|c|c|c|c|}
\hline Tahanan $(\Omega)$ & I rem (ampere) & Time (sec) & Kecepatan $(\mathrm{m} / \mathrm{s})$ \\
\hline 365 & 1.04 & 5.54 & 1.56 \\
\hline 300 & 1.42 & 4.8 & 2.13 \\
\hline 250 & 1.6566 & 4.483 & 2.4849 \\
\hline 200 & 2.2433 & 4.29 & 3.36495 \\
\hline 100 & 3.8466 & 3.84 & 5.7699 \\
\hline 60 & 5.4933 & 3.336 & 8.2399 \\
\hline
\end{tabular}

Berdasar hasil pada Tabel 3, dapat diperoleh grafik waltu pengereman dan arus pengereman fungsi nilai tahanan pengereman seperti ditunjukkan pada Gambar 9.
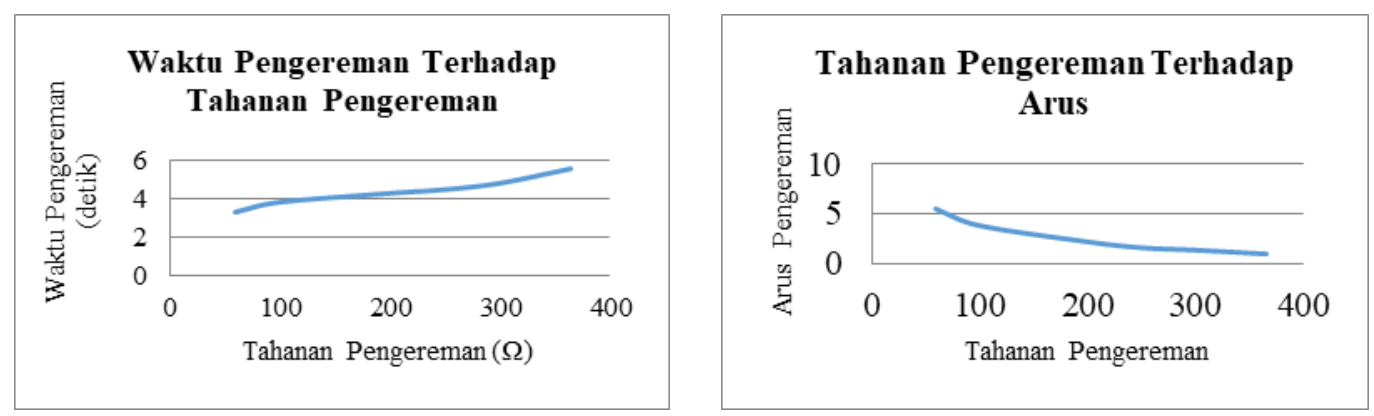

Gambar 9. Grafik Waktu dan Arus Pengereman Fungsi Nilai Tahanan Pengereman Pada Pengujian Berbeban

Dari Gambar 9 dapat dilihat bahwa waktu pengereman akan lebih pendek jika nilai tahanannya lebih kecil. Nilai tahanan yang kecil ini menghasilkan arus pengereman yang paling besar. Dengan kata lain, agar pengereman berlangsung cepat, maka arus yang diperlukan akan besar.

\section{Pengujian Di Jalan Dengan Beban Mobil dan Manusia}

Pengujian pengereman di jalan dengan beban seluruh mobil dan seorang pengemudi dilakukan di jalan data dalam kampus Politeknik Negeri Samarinda. Dokumentasinya ditunjukan pada Gambar 10. 


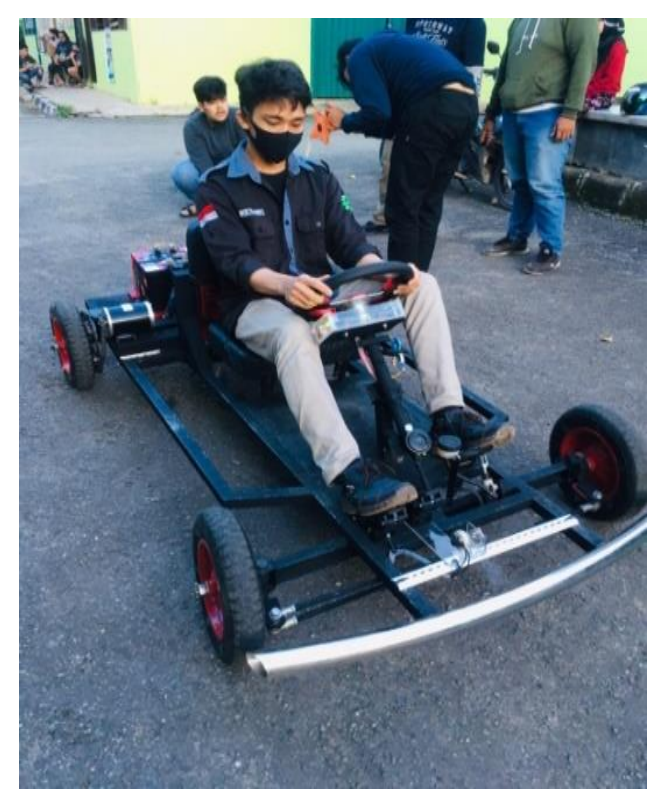

Gambar 10. Pengujian Motor Dijalan Menggunakan Beban

Pada proses pengujian, mobil mula-mula berhenti, setelah itu dijalankan dan dipercepat hingga mencapai kecepatan 9 meter/detik $(9 \mathrm{~m} / \mathrm{s})$. Ketika kecepatan itu dicapai, maka rem mobil diaktifkan. Pada percobaan ini, pengereman tidak dilakukan dengan menginjak pedal, tetapi dengan mengatur resistor pengereman pada nilai tertentu. Pengereman terjadi ketika relay memutus hubungan antara sumber dengan motor. Tiga nilai resistansi yang dipilih adalah $50 \Omega, 70 \Omega$, dan $90 \Omega$. Pada masingmasing pengujian pengereman, data tegangan, arus, dan kecepatan otomatis diukur oleh mikrokontroler Arduino secara periodik. Berikut ditunjukkan hasil pengukuran tegangan, arus, kecepatan mobil, dan jarak yang ditempuh hingga berhenti. Untuk nilai tahanan $50 \Omega, 70 \Omega$, dan $90 \Omega$, berturut-turut ditunjukkan dalam Tabel 4, Tabel 5, dan Tabel 6.

Tabel 4. Data Hasil Pengujian Di Jalan Dengan Tahanan Pengereman $50 \Omega$

\begin{tabular}{|c|c|c|c|}
\hline No Sampel & Tegangan (V) & Arus (A) & Kecepatan (m/s) \\
\hline 1 & 0 & 0 & 0 \\
\hline 2 & 15 & 10 & 2 \\
\hline 3 & 23 & 18 & 4 \\
\hline 4 & 25 & 26 & 4 \\
\hline 5 & 27 & 26 & 5 \\
\hline 6 & 30 & 27 & 6 \\
\hline 7 & 35 & 31 & 7 \\
\hline 8 & 38 & 32 & 9 \\
\hline 9 & 42 & 34 & 6 \\
\hline 10 & 35 & 28 & 4 \\
\hline 11 & 29 & 25 & 2 \\
\hline 12 & 26 & 19 & 0 \\
\hline 13 & 19 & 14 & 0 \\
\hline 14 & 0 & 0 & 6 \\
\hline
\end{tabular}

Jarak yang ditempuh hingga berhenti adalah 18, 2 meter. 
120 Muhammad Ali Faisal Fadhilah, Cornelius Sarri, Masing, Prihadi Murdiyat. Rancang Bangun Pengereman Motor Direct Current Pada Mobil Listrik

Tabel 5. Data Hasil Pengujian Di Jalan Dengan Tahanan Pengereman $70 \Omega$

\begin{tabular}{|c|c|c|c|}
\hline No sampel & Tegangan (V) & Arus (A) & Kecepatan $(\mathbf{m} / \mathbf{s})$ \\
\hline 1 & 0 & 0 & 0 \\
\hline 2 & 12 & 15 & 2 \\
\hline 3 & 15 & 19 & 2 \\
\hline 4 & 18 & 22 & 3 \\
\hline 5 & 23 & 25 & 5 \\
\hline 6 & 27 & 25 & 5 \\
\hline 7 & 32 & 27 & 7 \\
\hline 8 & 36 & 27 & 7 \\
\hline 9 & 39 & 30 & 9 \\
\hline 10 & 43 & 32 & 6 \\
\hline 11 & 36 & 30 & 5 \\
\hline 12 & 31 & 27 & 3 \\
\hline 13 & 28 & 25 & 2 \\
\hline 14 & 24 & 21 & 0 \\
\hline 15 & 17 & 19 & 14 \\
\hline 16 & 14 & 0 & 2 \\
\hline 17 & 0 & 14 & 2 \\
\hline
\end{tabular}

Jarak yang ditempuh hingga berhenti adalah 32, 2 meter.

Tabel 6. Data Hasil Pengujian Di Jalan Dengan Tahanan Pengereman $90 \Omega$

\begin{tabular}{|c|c|c|c|}
\hline No sampel & Tegangan $(\mathbf{V})$ & Arus $(\mathbf{A})$ & Kecepatan $(\mathbf{m} / \mathbf{s})$ \\
\hline 1 & 0 & 0 & 0 \\
\hline 2 & 12 & 17 & 2 \\
\hline 3 & 15 & 19 & 3 \\
\hline 4 & 17 & 21 & 4 \\
\hline 5 & 19 & 21 & 4 \\
\hline 6 & 23 & 25 & 6 \\
\hline 7 & 27 & 25 & 6 \\
\hline 8 & 30 & 29 & 8 \\
\hline 9 & 32 & 29 & 9 \\
\hline 10 & 36 & 31 & 8 \\
\hline 11 & 40 & 34 & 6 \\
\hline 12 & 38 & 32 & 6 \\
\hline 13 & 35 & 30 & 4 \\
\hline 14 & 31 & 27 & 2 \\
\hline 15 & 29 & 27 & 2 \\
\hline 16 & 24 & 21 & 0 \\
\hline 17 & 19 & 17 & 46 \\
\hline 18 & 14 & 0 & 2 \\
\hline 19 & 0 & 16 & 3 \\
\hline
\end{tabular}

Jarak yang ditempuh hingga berhenti adalah 38,3 meter. 
Karena pengukuran dilakukan secara periodik oleh mikrokontroler, tampak bahwa semakin besar nilai tahanan pengereman jumlah sampel yang diambil lebih banyak. Hal ini menandakan bahwa waktu berhenti mobil lebih lama dibanding ketika nilai tahanan paling kecil. Hal ini juga dibuktikan dengan jarak tempuh untuk berhenti yang panjang.

\section{KESIMPULAN} berikut:

Dari data hasil pengukuran dan pembahasan yang dilakukan, dapat diperoleh kesimpulan sebagai

1. Pada saat pengereman, semakin kecil nilai tahanan yang diberikan semakin besar arus yang didapat, dan sebaliknya.

2. Semakin kecil nilai tahanan pada rem akan semakin cepat waktu pengereman/berhentinys mobil listrik.

3. Pengereman sebaiknya dilakukan bertahap agar motor tidak langsung berhenti mendadak, yang mungkin dapat menyebabkan kerusakan pada motor.

\section{DAFTAR PUSTAKA}

[1] S. Agustina dan N. Nugroho, "Analisa Motor DC (Direct Current) Sebagai Penggerak Mobil Listrik", Jurnal Mikrotiga vol. 2 no. 1, pp. 28-34, 2015.

[2] Arofah, "Sistem Pengereman Mobil Golf Listrik", Skripsi, Universitas Sebelas Maret Surakarta, 2018.

[3] P. Hadi, "Sistem Kendali Rem Mobil Listrik Berbasis Arduino Uno", Skripsi, Universitas Muhammadiyah Ponorogo, 2019.

[4] Kho, "Pengertian Motor DC dan Prinsip Kerjanya", https://teknikelektronika.com/pengertian-motor-dcprinsip-kerja-dc-motor/ (accessed Jan. 15, 2020).

[5] ----, "Components of an Electric Linear Actuator", https://www.timotion.com/en/news/ news_content/ blog-articles/general/part-2\%3A-components-of-an-electric-linear-actuator?upcls=1481266229\&amp; guid $=1496378846$ (accessed Jan. 15, 2020).

[6] G. A. Pratama, "Perbedaan Brushed dan Brushless Motor Pada RC", https://gilangajip.com/perbedaanbrushed-dan-brushless-motor-rc/ (accessed Jan. 15, 2020).

[7] E. Y. Novriandi dan Noveri Lysbetti M, "Pengereman Motor Arus Searah (DC) Berbasis Mikrokontroler Atmega8535", Rekayasa dan Teknol. Elektro vol. 2 no. 1, pp. 1-9, 2015.

[8] R. E. Sitinjak, "Perbandingan Pengereman Motor DC Penguatan Seri Dengan Metode Dinamis dan Plugging", Skripsi, Fakultas Teknik, Universitas Sumatera Utara, 2008.

[9] Bosch, "Relay Bosch", br.bosch-automotive.com (accessed Jul. 25, 2020). 